\title{
Increase in scout trips due to forager removal in Atta sexdens (Hymenoptera, Formicidae) (Forel, 1908)
}

\author{
Mariana Silva Brugger ${ }^{\mathrm{a}}$, Roberto da Silva Camargo ${ }^{\mathrm{a}, \mathrm{c}, *}$, Luiz Carlos Forti ${ }^{\mathrm{a}}$, \\ Juliane Floriano Santos Lopes ${ }^{\mathrm{b}}$ \\ ${ }^{a}$ Laboratório de Insetos Sociais-Praga, Departamento de Produção Vegetal - Setor Defesa Fitossanitária, FCA/UNESP, P.O. Box 237, Zip Code 18603-970, Botucatu, São \\ Paulo, Brazil \\ b PPGCB: Comportamento e Biologia Animal, PPG: Ecologia, Instituto de Ciências Biológicas - ICB, Universidade Federal de Juiz de Fora - UFJF, Campus Universitário \\ Martelos, Zip Code 36036-330, Juiz de Fora, Minas Gerais, Brazil \\ ${ }^{\mathrm{c}}$ Laboratory of Agricultural Entomology, Agronomy Department, College of Agricultural Sciences, University of Western São Paulo [Universidade do Oeste Paulista] \\ (UNOESTE), Presidente Prudente, São Paulo, Brazil
}

\section{A R T I C L E I N F O}

\section{Keywords:}

Recruitment

Foraging

Interaction

Self-organized system

Leaf-cutting ants

\begin{abstract}
A B S T R A C T
Social information exchange through physical contacts and chemical trail deposition forms the basis of food recruitment in leaf-cutting ants. The scout initiates the process and passes the information to nestmates that recruit more foragers, thus amplifying the stimulus and ensuring the success of foraging. An interruption of the contact between workers and a reduction in trail laying can diminish the effectiveness of mass recruitment and alter scouting activity and forager flow. This study verified an increase in scout trips as a consequence of inbound workers (with or without a plant load) removal during Atta sexdens foraging, sustaining the outbound flow of foragers, and consequently foraging activity, either through direct contact or chemical trail deposition. Data indicate as one of the roles of unladen workers along the foraging trail must be to stimulate other workers to go out and so speed up the recruitment process The remarkable ability to organize themselves without central control is a major strength of social insects and the increase in scouting activity observed here is an example of this behavioral flexibility in leaf-cutting ants. Although foraging performance is enhanced through communication between workers, the simple adjustment in scouting activity can maintain the outbound flow of foragers which is an essential activity of the colony.
\end{abstract}

\section{Introduction}

Communication is a central component of life (Hölldobler, 1999) and access to information through conspecifics is an important benefit of social life (Farji-Brener et al., 2010). How individuals communicate and process information is crucial for a variety of processes, including the foraging success of social insects (Camazine et al., 2001; Detrain and Deneubourg, 2008).

Foraging strategies can be quickly adapted to environmental changes due to the behavioral flexibility and communication among ant workers (Seeley et al., 1991; Gordon, 1996). Thus, the efficiency of this activity is assured by an adequate number of workers engaged in the different tasks that comprise foraging per se (Oster and Wilson, 1978; Gordon, 1989, 1996). However, little is known about how workers achieve this intricate adaptation of task allocation in order to satisfy colony needs in response to environmental changes and how much the success of foraging relies on the recruitment process.
By antennal contacts, which must not be considered as random collisions, workers can access local density and so we can suggest that contact rates have some function in the self-organization process of ant colonies as these contacts act as local cues making the workers engage in the tasks immediately required by the colony (Theraulaz et al., 1998; Beshers and Fewell, 2001). Actually, contacts with laden and unladen ants had an influence on foraging efficiency, suggesting that in leafcutting ants information transfer occurs during head-on contacts, whether or not inbound ants carry a leaf fragment (Bouchebti et al., 2015).

Food recruitment is controlled both by scout behavior (De Biseau and Pasteels, 2000) and by the decision-making process of forager workers but also depends on the interaction with other workers and individual differences in stimulus responses. Colonies constantly change their foraging efforts according to the previous experience of the scouts (Roces and Hölldobler, 1994; Roces, 2002) and to the forager experience combined with information transmitted by the scouts (Lopes

\footnotetext{
* Corresponding author

E-mail addresses: camargobotucatu@yahoo.com.br (R.d.S. Camargo), julianeflopes@yahoo.com.br (J.F.S. Lopes).
} 
et al., 2004). Evidence indicates that workers use their previous experience as cues (Howard et al., 1996). According to De Biseau and Pasteels (2000), foragers inside the nest have different response thresholds to the recruitment signals, a fact that probably interferes with the results obtained in foraging studies.

The relationship between individual scout behavior and mass recruitment makes foraging a particularly complex process in Atta species (Jaffé and Howse, 1979). Once a food source is discovered, the scout stimulates workers to forage which, in turn, amplify the stimulus by recruiting more foragers during homing. This recruitment is mediated by pheromone deposition along the trail (Jaffé and Howse, 1979) and by contacts (head-on collisions, antennal boxing) between nestmates (Burd and Aranwela, 2003). Thus, one may suppose that the removal of all homing individuals, i.e., those returning to the colony with or without plant material, stops the communication between foragers and the recruitment task will be restricted to the scout. To compensate for the lack of worker recruitment, it is expected that the scout persists in mobilizing workers for foraging. In this case, if the scout activates recruitment in the absence of the forager-forager stimulus, the number of trips between the colony and food source should be greater in the absence of homing forager workers when compared to situations in which worker recruitment, and consequently forager communication, is not interrupted.

Within this context, the time spent foraging would be higher in the absence of worker recruitment. In order to compensate for the lack of communication between workers, the flow of unloaded inbound workers that only return to the colony for recruitment would also be higher, a fact that will reduce leaf delivery rates. In this study, we tested these premises by verifying how the absence of communication between Atta sexdens foragers that travel in opposite directions along the trail affects foraging activity.

\section{Material and methods}

Four Atta sexdens colonies originating from Botucatu, Brazil with approximately $3 \mathrm{~L}$ of symbiotic fungus and about 2000-7000 workers were used to perform the experiments. They were reared at the laboratory for four years at $26 \pm 5{ }^{\circ} \mathrm{C}$ and fed daily with fresh leaves. Each colony was connected individually by glass bridges (length: $2 \mathrm{~m}$; width: $2.5 \mathrm{~cm})$ to a foraging arena that contained 50 plant disks $(0.5 \mathrm{~cm}$ in diameter) of Acalypha wilkesiana. It was applied a cleaned trail for each experimental assay (alcohol 70\%).

The first worker, here after called scout that reached the foraging arena and returned to the nest was marked on the pronotum with a dot of non-toxic ink (Lopes et al., 2004). After marking the scout, workers who were inside the foraging arena were removed. The other workers in the trail were removed, according to each one of the treatments. Every trip performed by the marked scout between the nest and foraging arena was recorded, as well as the flow of loaded and unloaded inbound workers until all 50 disks have been transported to the colony. We also registered the outbound workers flow until the total transport of the disks. We considered as one scout trip the round trip between the foraging arena and the nest.

During the scout trips, three types of manipulation were performed on different days in each colony:

Treatment NI (no inbound): All foragers that returned to the colony with or without a plant load were removed and transferred to a clean separate box in order to interrupt the contact between workers, pheromone trail deposition, and consequently worker recruitment. Only the marked scout was allowed to travel between the colony and foraging arena.

Treatment NL(no laden): Only laden foragers were removed and kept in a clean separate box, thus interrupting the homing of laden workers. The marked scout and unladen workers were allowed to travel between the colony and foraging arena.

Control treatment: None of the workers returning to the colony was removed, thus not interfering with worker recruitment.

A fixed point $1 \mathrm{~cm}$ apart from the foraging arena exit was used to remove the workers according to treatment. This removing method has been used in previous studies (Burd, 2000; Dussutour et al., 2007, 2009, Bouchebti et al., 2015) and does not appear to have caused any disturbance in our experiment. Each treatment was repeated in each of the four colonies, totaling 12 experimental assays. At each assay, just one worker - the marked one - was observed. The same individual was not used in the next repetitions. The colonies were not fed for $24 \mathrm{~h}$ before each experimental event to ensure high foraging activity (Lopes et al., 2004; Herz et al., 2008).

To investigate the effect of treatment on the number of scout trips between the food source and the colony, we used a linear mixed effect model (GLMM) with treatment as a fixed factor flowed by Tukey contrasts. In all models, the colony was included as a random factor. To comply with the assumption of normality and homoscedasticity of the model residuals, the variables number of scout trips and laden worker rate were $\log 10$-transformed (Bolker et al., 2009; Bernadou et al., 2011, 2016). The variance explained by the models was assessed by the value of the marginal $R^{2}$ which is related with the fixed factors and the conditional $R^{2}$ which is related with both fixed and random factors (Nakagawa and Schielzeth, 2013). The same procedure was used to verify if there would be any effect of the treatments on the laden worker rate (laden inbound workers/total inbound workers).

Using the outbound worker frequency data we analyzed the flow of the whole foraging process registered for each treatment. Frequency distribution of outbound worker flow during $5 \mathrm{~min}$ intervals was compared between the treatments using the Kolmogorov-Smirnov (KS) test.

All analyses were carried out using the R software version 3.3.3 ( $R$ Core Team, 2017) and a level of significance of $5 \%$ was adopted.

\section{Results}

The number of trips by scouts differed between treatments (GLMM: $F_{2}=7.79, P=0.02, R_{\text {marg }}^{2}=0.57, R_{\text {cond }}^{2}=0.59$ ) and was higher when no inbound workers were allowed in the trails (NI) then there was no worker removal (control) $(\mathrm{Z}=3.32, \mathrm{P}=0.002)$ and when just the loaded workers were removed (NL) $(\mathrm{Z}=-3.51, \mathrm{P}=0.001)$ (Fig. 1).

Transport of leaves by scouts was a usual event being registered just 1 time at the control treatment and 2 times at the No Laden treatment.

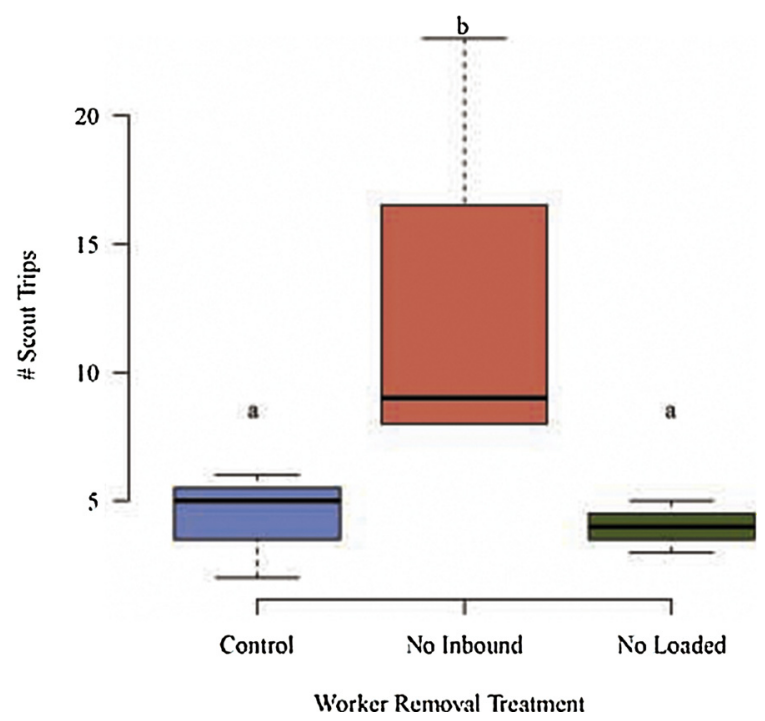

Fig. 1. Distribution of the number of scout trips as a function of the worker removal treatments (Control $=$ no ants removal; No inbound $=$ all inbound workers removal; No laden = All laden inbound workers removal) during Atta sexdens foraging. Boxplots represent median and percentiles. Whiskers represent smallest and largest values. 


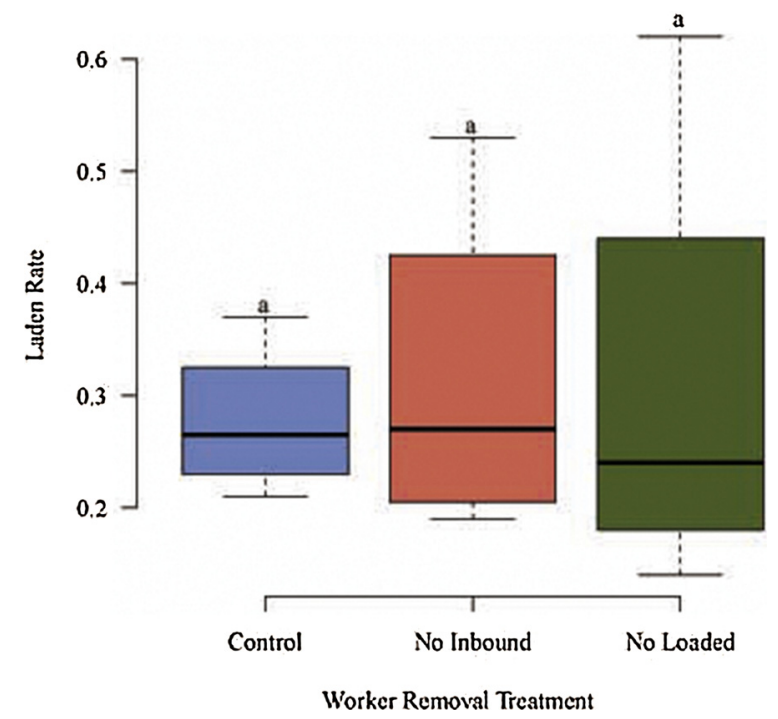

Fig. 2. Proportion of inbound Atta sexdens workers returning to the colony with a plant load according to treatments (Control = no ants removal; No inbound = all inbound workers removal; No laden = All laden inbound workers removal). Boxplots represent median and percentiles. Whiskers represent smallest and largest values.

The permanency of the scout inside the nest between the trips was in average: $2 \mathrm{~min} 7.7 \mathrm{~s}, 3 \mathrm{~min} 48.22 \mathrm{~s}$ and $2 \mathrm{~min} 34.3 \mathrm{~s}$ for the treatments Control, No Laden, No Inbound, respectively.

The laden worker rate did not differ between treatments (GLMM: $\mathrm{F}_{2}=0.12, \mathrm{P}=0.88, R_{\text {marg }}^{2}=0.007, R_{\text {cond }}^{2}=0.68$ ) (Fig. 2), indicating that despite no contacts between outbound and inbound workers, leaf delivery would be sustained despite workers removal, what means that the scout could sustain the recruitment.

Frequency distribution of outbound worker flow has a significant difference between No Laden and Control ( $\mathrm{D}=0,11$; $\mathrm{p}<0,001$ ), No Inbound and Control $(\mathrm{D}=0,13 ; \mathrm{p}<0,001)$ between No Inbound and No Laden ( $=0,16 ; p<0,001$ ) (Fig. 3). The first outbound worker left the nest about after $3 \mathrm{~min}$ in the treatments Control and No Inbound and after $2 \mathrm{~min}$ in the treatment No Laden. The last outbound worker passage occurred at $25 \mathrm{~min}, 28 \mathrm{~min}$ and $50 \mathrm{~min}$ in the treatments Control, No Laden, and No Inbound, respectively. Both information means that there was a delay in foraging process when all the inbound workers were removed.

\section{Discussion}

The removal of all inbound workers promoted an increase in scout

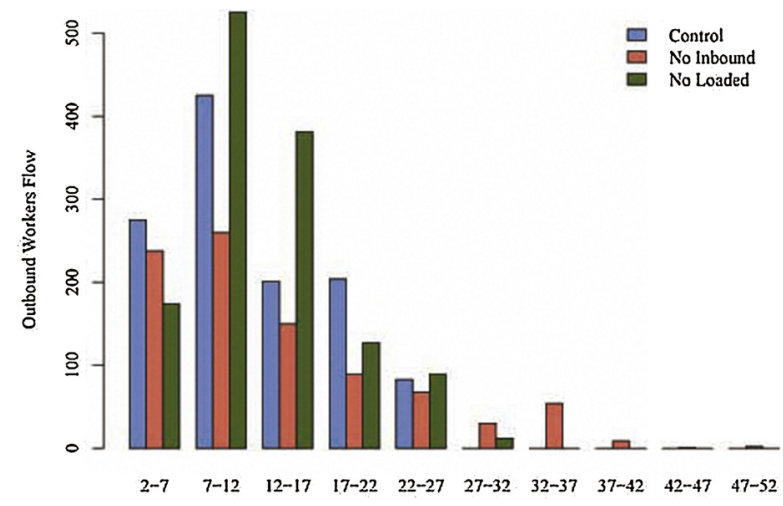

Fig. 3. Frequency distribution of outbound worker flow in Atta sexdens at each treatment (Control = no ants removal; No inbound = all inbound workers removal; No laden = All laden inbound workers removal). trips, showing that the scout modified its own activity in order to sustain the foraging process. Actually, by raising the number of trips, scout workers were able to recruit nestmates for foraging, as there is no effect of workers removal (all inbound or just the laden ones) over laden workers rate. However, total foraging time spent for transport the same number of leaf fragments increased when all inbound workers were removed, demonstrating that one of the roles of unladen workers along the foraging trail must be to stimulate other workers to go out and so speed up the recruitment process, probably via antennal contacts.

In the present study, although $A$. sexdens foragers were deprived of contact with nestmates, foraging activity was maintained as workers continued to transport leaves. The same is observed in Pogonomyrmex barbatus in which the absence of inbound workers promotes a delay and a decrease in foraging activity, but the colony does not stop foraging (Gordon, 2002).

The chemical stimulus (trail pheromone deposition) in combination with the physical stimulus (physical contacts) plays an important role in the success of resource collection. A brief contact with a nestmate can influence task allocation among workers (Greene and Gordon, 2003), confirming the existence of an effective communication system in which the contacts are not merely random.

Evidence indicates that in many ant species physical contact with loaded workers stimulates other workers to leave the nest (Le Breton and Fourcassié, 2004; Lopes et al., 2004; Dussutour et al., 2007; FarjiBrener et al., 2010). Here we show evidence that unloaded inbound workers also play a role in the recruitment process.

Unloaded inbound workers removal interfered in ant trail densities and so on time lapse between interactions and chemical trail deposition which both affect foraging decisions (Jaffé, 1980; O'Donnell, 2001; Burd, 2006; Dussutour et al., 2007). Actually, ant foraging trails are accurately self-adjusted by their own density. Trail crowding has been shown to reduce chemical trail deposition, while empty trail turns has an opposite effect (Czaczkes et al., 2014).

In fact, encounters exert a major influence on worker behavior as demonstrated by the observation that foraging activity was lower when all inbound workers were removed compared to the situation when only laden inbound workers were removed. In Atta cephalotes, workers are able to regulate recruitment activity by adjusting their behavior according to the number of workers on the trail (Jaffé and Howse, 1979). Encounters with unladen nestmates motivate workers to collect resources (Jaffé and Howse, 1979). On the other hand, in P. barbatus, only laden workers influence foraging activity (Gordon, 2002). It is important to highlight that in both cases the behavior adjustment is modulated by worker encounters without the need to use their memory or to monitor colony activity (Schafer et al., 2006).

The capacity of behavior adjustment in response to changes without any central control is the key to the success of social insects (Bonabeau et al., 1997). This study shows that the increase in scouting activity is a simple behavior adjustment that contributes to the maintenance of an essential activity of the colony (i.e. foraging) which is achieved by the lack of communication between and outbound workers. We suggest unloaded inbound workers have a more important role than the laden inbound workers in the recruitment.

\section{Compliance with ethical standards}

Author Mariana S Brugger has received a doctoral scholarship from CNPq (143495/2011-9). Author Luiz Carlos Forti has received research grants from CNPq (301917/2009-4).

Ants were collected and handled with the permission of the IBAMA (license 16284-1).

\section{Acknowledgment}

Luiz Carlos Forti was the recipient of a grant from Conselho Nacional de Desenvolvimento Cientifico e Tecnológico (Grant 301718/ 
2013-0).

\section{References}

Bernadou, A., Espadaler, X., Dos-Reis, V., Fourcassié, V., 2011. Effect of substrate roughness on load selection in the seed-harvester ant Messor barbarus L. (Hymenoptera, Formicidae). Behav. Ecol. Sociobiol. 65, 1763. http://dx.doi.org/10. 1007/s00265-011-1184-4.

Bernadou, A., Felden, A., Moreau, M., Moretto, P., Fourcassié, V., 2016. Ergonomics of load transport in the seed harvesting ant Messor barbarous Linnaeus, 1767: morphology influences transportation method and efficiency. J. Exp. Biol. 219, 2920-2927. http://dx.doi.org/10.1242/jeb.141556.

Beshers, S.N., Fewell, J.H., 2001. Models of division of labor in social insects. Annu. Rev. Entomol. 46, 413-440.

Bolker, B.M., Brooks, M.E., Clark, C.J., Geange, S.W., Poulsen, J.R., Stevens, M.H.H., White, J.S.S., 2009. Generalized linear mixed models: a practical guide for ecology and evolution. Trends Ecol. Evol. 24 (3), 127-135.

Bonabeau, E., Theraulaz, G., Deneubourg, J.L., Aron, S., Camazine, S., 1997. Self-organization in social insects. Trends Ecol. Evol. 12, 188-193.

Bouchebti, S., Ferrere, S., Vittori, K., Latil, G., Dussutour, A., Fourcassié, V., 2015. Contact rate modulates foraging efficiency in leaf cutting ants. Sci. Rep. 5.

Burd, M., 2000. Foraging behaviour of Atta cephalotes (leaf-cutting ants): an examination of two predictions for load selection. Anim. Behav. 60, 781-788.

Burd, M., Aranwela, N., 2003. Head-on encounter rates and walking speed of foragers in leaf-cutting ant traffic. Insectes Soc. 50, 3-8.

Burd, M., 2006. Ecological consequences of traffic organization in ant societies. Physica A $372,124-131$.

Camazine, S., Deneubourg, J.L., Franks, N., Sneyd, J., Bonabeau, E., Theraulaz, G., 2001. Self-Organization in Biological Systems. Princeton University Press, Princeton.

Czaczkes, T.J., Grüter, C., Ratnieks, F.L.W., 2014. Rapid up- and down-regulation of pheromone signaling due to trail crowding in the ant Lasius niger. Behaviour 151 (5), 669-682. http://dx.doi.org/10.1163/1568539X-00003157.

De Biseau, J.C., Pasteels, J.M., 2000. Response thresholds to recruitment signals and the regulation of foraging intensity in the ant Myrmica sabuleti (Hymenoptera, Formicidae). Behav. Proc. 48, 137-148.

Detrain, C., Deneubourg, J.L., 2008. Collective decision-making and foraging patterns in ants and honeybees. Adv. Insect Physiol. 35, 123-173.

Dussutour, A., Beshers, S., Deneubourg, J.L., Fourcassié, V., 2007. Crowding increases foraging efficiency in the leaf-cutting ant Atta colombica. Insectes Soc. 54, 158-165.

Dussutour, A., Deneubourg, J.L., Beshers, S., Fourcassie, V., 2009. Individual and collective problem-solving in a foraging context in the leaf-cutting ant Atta colombica. Anim. Cognit. 12, 21-30.

Farji-Brener, A.G., Amador-Vargas, S., Chinchilla, F., Escobar, S., Cabrera, S., Herrera, M.I., Sandoval, C., 2010. Information transfer in head-on encounters between leafcutting ant workers: food, trail condition or orientation cues? Anim. Behav. 79,
343-349.

Gordon, D.M., 1989. Dynamics of task switching in harvester ants. Anim. Behav. 38, 194-204.

Gordon, D.M., 1996. The organization of work in social insect colonies. Nature 380, 121-124.

Gordon, D.M., 2002. The organization of work in social insect colonies. Complexity 8 , 43-46. http://dx.doi.org/10.1002/cplx.10048.

Greene, M.J., Gordon, D.M., 2003. Cuticular hydrocarbons inform task decisions. Nature $423,32$.

Herz, H., Hölldobler, B., Roces, F., 2008. Delayed rejection in a leaf-cutting ant after foraging on plants unsuitable for the symbiotic fungus. Behav. Ecol. 19 (3), 575-582.

Hölldobler, B., 1999. Multimodal signals in ant communication. J. Comp. Physiol. A 184, 129-141.

Howard, J.J., Henneman, M.L., Cronin, G., Fox, J.A., Hormiga, G., 1996. Conditioning of scouts and recruits during foraging by a leaf-cutting ant, Atta colombica. Anim. Behav. 52, 299-306.

Jaffé, K., Howse, P.E., 1979. The mass recruitment system of the leaf cutting ant, Atta cephalotes (L.). Anim. Behav. 27, 930-939.

Jaffé, K., 1980. Theoretical analysis of the communication system for chemical mass recruitment in ants. J. Theor. Biol. 84, 589-609.

Le Breton, J., Fourcassié, V., 2004. Information transfer during recruitment in the ant Lasius niger L. (Hymenoptera, Formicidae). Behav. Ecol. Sociobiol. 55, 242-250.

Lopes, J.F.S., Forti, L.C., Camargo, R.S., 2004. The influence of the scout upon the decision-making process of recruited workers in three Acromyrmex species (Formicidae: Attini). Behav. Proc. 67, 471-476.

Nakagawa, S., Schielzeth, H., 2013. A general and simple method for obtaining $\mathrm{R}^{2}$ from generalized linear mixed-effects models. Methods Ecol. Evol. 4 (2), 133-142. http:// dx.doi.org/10.1111/j.2041-210x.2012.00261.x.

O'Donnell, S., 2001. Social aggression and task performance in a swarm-founding eusocial wasp (Polybiaoccidentalis, Hymenoptera: Vespidae). Behav. Ecol. Sociobiol. 12 (3), 353-359.

Oster, G.F., Wilson, E.O., 1978. Caste and Ecology in the Social Insects. Princeton University Press, Princeton.

R Core Team, 2017. R: A Language and Environment for Statistical Computing. R Foundation for Statistical Computing, Vienna, Austria.

Roces, F., Hölldobler, B., 1994. Leaf density and a trade-off between load-size selection and recruitment behavior in the ant Atta cephalotes. Oecologia 97, 1-8.

Roces, F., 2002. Individual complexity and self-organization in foraging by leaf-cutting ants. Biol. Bull. 202, 1-7.

Schafer, R.J., Holmes, S., Gordon, D.M., 2006. Forager activation and food availability in harvester ants. Anim. Behav. 71, 815-822.

Seeley, T.D., Camazine, S., Sneyd, J., 1991. Collective decision-making in honey bees: how colonies choose among nectar sources. Behav. Ecol. Sociobiol. 28, 277-290.

Theraulaz, G., Bonabeau, E., Deneubourg, J., 1998. The origin of nest complexity in social insects. Complexity 3, 15-25. 